\title{
HACEK Infective Endocarditis: Characteristics and Outcomes from a Large, Multi-National Cohort
}

\author{
Stephen T. Chambers ${ }^{1 *}$, David Murdoch ${ }^{1}$, Arthur Morris ${ }^{2}$, David Holland ${ }^{3}$, Paul Pappas ${ }^{4}$, Manel Almela ${ }^{5}$, \\ Nuria Fernández-Hidalgo ${ }^{6}$, Benito Almirante ${ }^{6}$, Emilio Bouza ${ }^{7}$, Davide Forno ${ }^{8}$, Ana del Rio ${ }^{9}$, \\ Margaret M Hannan ${ }^{10}$, John Harkness ${ }^{11}$, Zeina A. Kanafani ${ }^{12}$, Tahaniyat Lalani ${ }^{13}$, Selwyn Lang ${ }^{14}$, \\ Nigel Raymond ${ }^{15}$, Kerry Read ${ }^{16}$, Tatiana Vinogradova ${ }^{17}$, Christopher W. Woods ${ }^{18}$, Dannah Wray ${ }^{19}$, \\ G. Ralph Corey ${ }^{20}$, Vivian H. Chu ${ }^{21}$, International Collaboration on Endocarditis Prospective Cohort Study \\ (ICE-PCS) Investigators
}

1 Department of Pathology, University of Otago, Christchurch and Christchurch Hospital, Christchurch, New Zealand, 2 Microbiology Laboratory, Auckland City Hospital, Auckland, New Zealand, 3 Microbiology Laboratory, Middlemore Hospital, Auckland, New Zealand, 4 Duke Clinical Research Institute, Duke University Medical Centre, Durham, North Carolina, United States of America, 5 Department of Microbiology, Hospital Clinic - IDIBAPS, University of Barcelona, Barcelona, Spain, 6 Infectious Diseases Department, Hospital Universitari Vall d'Hebron, Barcelona, Spain, 7 Clinical Microbiology and Infectious Diseases Service, Hospital General Universitario Gregorio Marañón, Madrid, Spain, 8 Cardiology Department, Maria Vittoria Hospital, Torino, Italy, 9 Department of Clinical Medicine, Infectious and Tropical Diseases, Hospital Clinic - IDIBAPS, University of Barcelona, Barcelona, Spain, 10 Department of Medical Microbiology, Mater Hospitals, Dublin, Ireland, 11 Department of Microbiology, St. Vincent's, Sydney, New South Wales, Australia, 12 Division of Infectious Diseases, American University of Beirut, Beirut, Lebanon, 13 Infectious Disease Clinical Research Program, Uniformed Services University, Bethesda, Maryland, United States of America, 14 Department of Microbiology, Middlemore Hospital, Auckland, New Zealand, 15 Department of Infectious Diseases, Wellington Hospital, Wellington, New Zealand, 16 Department of Infectious Diseases, North Shore Hospital, Auckland, New Zealand, 17 Institute of Experimental Cardiology, Russian Medical State University, Moscow, Russia, 18 Departent of Medicine, VA Medical Centre, Durham, North Carolina, United States of America, 19 Infectious Disease Division, Medical University of South Carolina, Charleston, South Carolina, United States of America, 20 Infectious Diseases, Duke University Medical Center, Durham, North Carolina, United States of America, 21 Duke University Medical Center, Durham, North Carolina, United States of America

\begin{abstract}
The HACEK organisms (Haemophilus species, Aggregatibacter species, Cardiobacterium hominis, Eikenella corrodens, and Kingella species) are rare causes of infective endocarditis (IE). The objective of this study is to describe the clinical characteristics and outcomes of patients with HACEK endocarditis (HE) in a large multi-national cohort. Patients hospitalized with definite or possible infective endocarditis by the International Collaboration on Endocarditis Prospective Cohort Study in 64 hospitals from 28 countries were included and characteristics of HE patients compared with IE due to other pathogens. Of 5591 patients enrolled, $77(1.4 \%)$ had HE. HE was associated with a younger age (47 vs. 61 years; $p<0.001)$, a higher prevalence of immunologic/vascular manifestations $(32 \%$ vs. $20 \% ; p<0.008)$ and stroke $(25 \%$ vs. $17 \%$ p $=0.05)$ but a lower prevalence of congestive heart failure ( $15 \%$ vs. $30 \% ; p=0.004)$, death in-hospital ( $4 \%$ vs. $18 \% ; p=0.001)$ or after 1 year follow-up $(6 \%$ vs. $20 \% ; p=0.01)$ than IE due to other pathogens $(n=5514)$. On multivariable analysis, stroke was associated with mitral valve vegetations (OR 3.60; $\mathrm{Cl} 1.34-9.65 ; \mathrm{p}<0.01)$ and younger age (OR $0.62 ; \mathrm{Cl} 0.49-0.90 ; \mathrm{p}<0.01)$. The overall outcome of HE was excellent with the in-hospital mortality (4\%) significantly better than for non-HE $(18 \% ; \mathrm{p}<0.001)$. Prosthetic valve endocarditis was more common in HE (35\%) than non-HE (24\%). The outcome of prosthetic valve and native valve $\mathrm{HE}$ was excellent whether treated medically or with surgery. Current treatment is very successful for the management of both native valve prosthetic valve HE but further studies are needed to determine why HE has a predilection for younger people and to cause stroke. The small number of patients and observational design limit inferences on treatment strategies. Self selection of study sites limits epidemiological inferences.
\end{abstract}

Citation: Chambers ST, Murdoch D, Morris A, Holland D, Pappas P, et al. (2013) HACEK Infective Endocarditis: Characteristics and Outcomes from a Large, MultiNational Cohort. PLoS ONE 8(5): e63181. doi:10.1371/journal.pone.006318

Editor: Antonio Abbate, Virginia Commonwealth University, United States of America

Received December 6, 2012; Accepted April 1, 2013; Published May 17, 2013

Copyright: (c) 2013 Chambers et al. This is an open-access article distributed under the terms of the Creative Commons Attribution License, which permits unrestricted use, distribution, and reproduction in any medium, provided the original author and source are credited.

Funding: This work was supported by the American Heart Association 0675027N (VHC), educational grants from International Society of Cardiovascular Infectious Diseases, International Society of Chemotherapy, the "Ministerio de Sanidad y Consumo, Instituto de Salud Carlos III", Madrid, Spain, and the Spanish Network for Research in Infectious Diseases (REIPI RD06/0008) (MA, CGDM) and the Fundación Privada Máximo Soriano Jiménez (Barcelona, Spain) (CGDM). The funders had no role in study design, data collection adn analysis, decision to publish, or preparation of the manuscript.

Competing Interests: The authors have declared that no competing interests exist.

*E-mail: steve.chambers@cdhb.govt.nz

- Membership of the International Collaboration on Endocarditis Prospective Cohort Study (ICE-PCS) is provided in the Acknowledgments.

\section{Introduction}

The HACEK group of bacteria (Haemophilus species, Aggregatibacter species, Cardiobacterium hominis, Eikenella corrodens, and Kingella species) are a small, heterogeneous group of fastidious, gram- negative bacteria that frequently colonize the oropharynx and have long been recognised as a cause of infective endocarditis (IE). These organisms have been historically reported as causing infection in $<5 \%$ of patients of IE $[1,2]$, and $0.8-6 \%$ of patients in recent population-based studies [3-5]. 
Due to the relative rarity of HACEK endocarditis (HE), the clinical description and outcome has, of necessity, been derived from compilation of data from small case series and case reports [6-10]. These reports are limited by non-standardized data collection and selective reporting of patients. Consequently, the features of HE identified cannot be compared rigorously with other forms of IE.

The International Collaboration on Endocarditis Prospective Cohort Study (ICE-PCS) was designed to provide a large multinational resource of prospectively collected, well defined patients of IE using a standardised data set. The objective is to improve understanding of the clinical characteristics and outcome of IE in a multi-national cohort of patients. In this report we describe the characteristics of patients with HE, and compare the risk factors, clinical characteristics, and outcomes of HE with IE caused by other pathogens (non-HE).

\section{Patients and Methods}

\section{Database}

ICE-PCS has been described previously [11,12]. Briefly, participating members from 64 sites in 28 countries reported patients prospectively on a standard case report form from June 2000 through to September 2006. The case report form included 275 variables and was developed by ICE collaborators according to standard definitions [11]. All patients were included from sites that met performance criteria for participation. These criteria include the following: minimum enrolment of 12 patients per year in a centre with access to cardiac surgery; the presence of patient identification measures to ensure consecutive enrolment and to minimise ascertainment bias [11]; high quality data with query resolution.

\section{Ethical Statement}

Initial institutional review board approval for ICE-PCS came from the Duke International Centre. All participating sites had institutional review board or ethical committee approval or a waiver and informed consent (verbal or written) or a waiver of consent from all patients based on local standards as required by the Duke Coordinating Centre.

\section{Study Sample}

Patients in the ICE-PCS database were included in this study if they had definite or possible IE according to the modified Duke's criteria. HACEK isolates were identified and antibiotic susceptibility testing performed in the participating centres. Antibiotic therapy was decided by the treating physician at the individual study site.

\section{Definitions}

Infective endocarditis was defined according to the modified Duke Criteria [13]. Infective endocarditis was considered to be left sided if no right sided (tricuspid or pulmonary valve) vegetations were present on echocardiographic examination, surgery, or autopsy. Community-acquired IE was defined as signs or symptoms of IE developing before hospitalization in a patient without extensive out-of-hospital contact with health care interventions or systems. Hospital acquired IE was defined as symptom onset and diagnosis occurring in a patient hospitalized for more than 48 hours.Health care-associated infection was defined as cases in which signs or symptoms consistent with infective endocarditis developed before hospitalization in patients with extensive out-of-hospital contact with health care interventions. Extensive out of hospital intervention included one or more of the following,(1) receipt of intravenous therapy, wound care, or specialized nursing care at home within the 30 days prior to the onset of IE; (2) visiting a hospital or hemodialysis clinic or receiving intravenous chemotherapy within the 30 days before the onset of IE; (3) hospitalization in an acute care hospital for 2 or more days in the 90 days before the onset of IE; or (4) residing in a nursing home or long-term care facility $[14,15]$.

Cancer was defined as any malignant neoplasm except basal or squamous cell carcinomas of the skin. The category "other chronic diseases" included connective tissue or rheumatologic disease, chronic liver or kidney disease, chronic neurological conditions, and other chronic infectious and inflammatory conditions. A diagnosis of heart failure was accepted on the basis of clinical evaluation performed by the care team and defined according to the New York Heart Association classification system [16]. Stroke was defined as an acute neurological deficit of vascular aetiology lasting more than 24 hours [17]. Systemic embolisation included embolisation to any organ including the skin. Valve surgery included all surgery performed on heart valves at any time during hospitalisation regardless of urgency. Rates of surgery and mortality include events that occurred during the index hospitalisation and one year follow-up. Repeat IE was defined as a further episode of IE fulfilling the modified Duke criteria. Confirmed relapse was defined as a repeat episode caused by the same microorganism on molecular analysis, as the preceding episode; confirmed new infection as a repeat episode caused by a different species or the same species but a different strain by molecular analysis; and possible relapse as repeat episode caused by a microorganism of the same species within 6 months of the initial episode without molecular analysis [18].

\section{Geographic regions}

Geographic regions participating in ICE included the following: United States (10 sites), South America (9 sites from Argentina, Brazil, and Chile), Europe (27 sites from Austria, Croatia, France, Germany, Greece, Ireland, Italy, the Netherlands, Romania, Russia, Slovenia, Spain, Sweden, and the United Kingdom), Australia and New Zealand (9 sites), Asia and Middle East (8 sites in India, Israel, Lebanon, Malaysia, Saudi Arabia, Singapore, and Thailand,) and South Africa (1 site).

\section{Microbiological methods}

Blood cultures and sensitivity testing was performed by accredited laboratories using standard methods. Sensitivity testing was most commonly those of the Clinical and Laboratory Standards Institute (CLSI)

\section{Statistical analysis}

Continuous variables were represented as medians with $25^{\text {th }}$ and $75^{\text {th }}$ percentiles. Categorical variables were represented as frequencies and percentages of the specified group. Simple comparisons were made with the Wilcoxon rank-sum test or the chi square test as appropriate. For all tests, a $p$ value of 0.05 or less was considered statistically significant. Missing data for each variable were excluded from the denominator. Variables found to have a simple association with the outcome of interest $(p<0.10)$ were considered for the final multiple variable model in a stepwise fashion. The variables included in the final multiple variable adjusted regression model were selected based on a combination of statistical significance $(p<0.05)$ and clinical judgment. The generalized estimating equation method was used to produce consistent parameter estimates that measure association between the incidence of outcome and clinical covariates while accounting for the correlation in treatment and outcomes of patients from the 
same hospital. Final parameter estimates were converted to ORs with corresponding 95\% Wald CIs. All statistical analyses were performed using SAS version 9.2 (SAS Institute, Cary, NC, USA).

\section{Results}

Seventy seven $(1.4 \%)$ of 5591 patients diagnosed with IE in ICE-PCS had HACEK endocarditis (66 definite and 11 possible) and PVE was present in 27 (35\%). The prevalence of HE differed significantly between the study sites $(p=0.009)$, with a low prevalence in North America and a high prevalence in Australia/New Zealand. The HE cases by region were: North America (5/992, 0.5\%), South America (8/518, 1.5\%), Australia/ New Zealand (23/979, 2.3\%), Europe (35/2806, 1.2\%), Asia/ Middle East (5/277, 1.8\%), and Africa (1/19).

\section{Features of HE by species}

The HACEK isolates were speciated in 76 (99\%) cases with Haemophilus species the most common (40\%) (Table 1). Of all HACEK species, only Kingella spp. was not associated with an episode of prosthetic valve endocarditis (PVE). PVE was more common in $A$. actinomycetemcomitans than $H$. parainfluenzae IE (10, $67 \%$ v $5,18 \%$; respectively $\mathrm{p}<0.01)$. Clinical manifestations of IE of more than 1 months duration were recorded more often in $A$. actinomycetemcomitans $(8,53 \%)$ and Cardiobacterium IE $(6,55 \%)$ than $H$. parainfluenzae $(3,11 \%$; both $\mathrm{p}<0.01)$. Aortic valve vegetations were identified on echocardiography more commonly in Cardiobacterium IE $(8,89 \%)$ than in H. parainfluenzae $(6,32 \%$; $<0.05)$ and A. actinomycetemcomitans $(2,29 \% ; \mathrm{p}<0.05)$ IE. Mitral valve endocarditis was common in $H$. parainfluenzae $(10,53 \%)$ and $A$. actinomycetemcomitans $(6,86 \%)$. Of the five cases with Oslers' nodes four occurred with $A$. actinomycetemcomitans IE.

Table 1. HACEK organisms isolated from definite and probable cases of HACEK endocarditis.

\begin{tabular}{|c|c|}
\hline HACEK organisms & Number (\%) \\
\hline Haemophilus spp. & $31(40)$ \\
\hline Haemophilus parainfluenzae & $28(36)$ \\
\hline Haemophilus sp. other ${ }^{a}$ & $3(4)$ \\
\hline Aggregatibacter spp. & $26(34)$ \\
\hline Aggregatibacter actinomycetemcomitans & $15(20)$ \\
\hline Aggregatibacter aphrophilus & $5(6)$ \\
\hline Aggregatibacter paraphrophilus & $5(6)$ \\
\hline Aggregatibacter segnis & $1(1)$ \\
\hline Cardiobacterium spp. & $11(14)$ \\
\hline Cardiobacterium hominis & $10(13)$ \\
\hline Cardiobacterium valvarum & $1(1)$ \\
\hline Eikinella corrodens & $4(5)$ \\
\hline Kingella spp. & $4(5)$ \\
\hline Kingella kingii. & $2(3)$ \\
\hline Kingella denitrificans & $1(1)$ \\
\hline Kingella sp. & $1(1)$ \\
\hline HACEK (not otherwise specified) & $1(1)$ \\
\hline Total & 77 \\
\hline
\end{tabular}

\section{Clinical features of HACEK and non-HACEK endocarditis}

Baseline characteristics and predisposing factors of $\mathrm{HE}$ are shown in Table 2. The median age of patients with HE (47.4 years; IQR 35.6-57.1) was significantly lower than non-HE (60.5 years; IQR 45.3-72.7) and males predominated (56, 73\%). Factors more commonly associated with HE than Non-HE endocarditis were Osler's nodes $(7 \%$ vs $3 \%, \mathrm{p}=0.02)$ and vascular immunological phenomena $(32 \%$ vs $20 \%, \mathrm{p}=0.008)$ and the presence of mechanical valves $(30 \%$ vs $18 \%, p=0.02)$. Factors less commonly associated with HE than non-HE endocarditis were health care provision ( $1 \%$ vs $24 \%, \mathrm{p}<0.001)$, and diabetes mellitus $(8 \%$ vs $18 \%, \mathrm{p}=0.02)$. There was no difference in the proportion with fever or splenomegaly between HE and non-HE, nor with native valve predisposition for IE or congenital heart disease (Table 2).

\section{Transfers from another facility}

There was no difference in the number of cases transferred from another facility between $\mathrm{HE}(30,39 \%)$ and non-HE (2288, 41\%; $\mathrm{p}=0.6)$. In HE there were more cases transferred with native valve endocarditis (24, 80\% vs 23, 49\%; $\mathrm{p}=0.01)$, new or worsening murmurs $(20,67 \%$ vs $19,40 \% \mathrm{p}=0.008)$, regurgitation on echocardiography $(23,77 \%$ vs $23,49 \% ; p=0.02)$, and need for valvular surgery (aortic valve 11 , mitral valve 12 ) ( $23,77 \%$ vs 8 , $17 \% \mathrm{p}<0.001$ ) compared with those directly admitted. There was a borderline significant increase in stroke among transferees (11, $38 \%$ vs $8,17 \% ; \mathrm{p}=0.06)$ and $\mathrm{CHF}(7,32 \%$ vs $49 \% ; \mathrm{p}=0.10)$ and no difference in the numbers of cases with symptoms longer than 1 month $(5,17 \%$ vs $13,28 \% \mathrm{p}=0.41)$ or length of hospital stay (median 23 IQR 15-42 vs median 27 IQR $14-42, \mathrm{p}=0.56$ ).

\section{Diagnosis}

Blood cultures were drawn in all 77 patients with HE. Three of four patients with negative blood cultures had received antibiotics in the previous seven days. Additional culture positive sites were heart valves (20), joint fluid (2), pacemaker wires (1), urine (1), and other (5). One patient was diagnosed by PCR of infected tissue. Echocardiography was performed in $97 \%$ of HE (transthoracic only 15, transesophageal only 9, both transthoracic and transesophageal 51). Vegetations were identified in a lower proportion in HE than non-HE $(71 \%$ vs $83 \%, p=0.01)$ (Table 2). There was no difference in the proportions of mitral and aortic valve vegetations identified between $\mathrm{HE}$ and non-HE. Only 1 case of tricuspid valve endocarditis was recorded in HE. New regurgitation and paravalvular complications were not significantly different from non-HE (Table 2).

\section{Antimicrobial susceptibility testing}

The causative organisms are shown in table 1. Of the isolates tested 24/25 (96\%) were penicillin susceptible (1 resistant strain of A. aphrophilus), 48/49 (98\%) were ampicillin susceptible (1 resistant strain, of $A$. aphrophilus), 50/50 (100\%) were ceftriaxone susceptible, and 30/32 (94\%) were gentamicin susceptible (2 resistant strains of $H$. parainfluenzae).

\section{Treatment}

Antimicrobial therapy was reported in $50(65 \%)$ patients. Of these $37(74 \%)$ were treated with ceftriaxone (in combination with an aminoglycoside in 17 and ampicillin in 6), 6 with a penicillin derivative (ampicillin in 3, penicillin $\mathrm{G}$ in 2, and penicillinaseresistant penicillin in one, in combination with an aminoglycoside), and 3 with cefazolin/cefalothin (in combination with an aminoglycoside), and 4 unspecified. All cases of HE were treated with antimicrobial agents that would be active as predicted by 
Table 2. Important features of HACEK endocarditis compared with all other causes of infective endocarditis in database*.

\begin{tabular}{|c|c|c|c|}
\hline & HACEK Endocarditis $n=77$ & $\begin{array}{l}\text { Non-HACEK Endocarditis } \\
n=5514\end{array}$ & $P$ value \\
\hline \multicolumn{4}{|l|}{ Clinical Features } \\
\hline Median age (interquartile range), $y$ & $47.4(35.6-57.1)$ & $60.5(45.3-72.7)$ & $<0.001$ \\
\hline Prosthetic valve endocarditis & 27/77 (35) & 1298/5514 (24) & 0.07 \\
\hline Manifestations $>1$ month & 18/77(23) & $1174 / 5294(22)$ & 0.68 \\
\hline Osler's nodes & $5 / 71(7)$ & 132/5260 (3) & 0.02 \\
\hline Conjunctival haemorrhages & $6 / 72(8)$ & 214/5261 (4) & 0.07 \\
\hline Vascular/immunologic evidence of endocarditis & $25 / 77(32)$ & $1118 / 5514(20)$ & 0.008 \\
\hline \multicolumn{4}{|l|}{ Risk factors } \\
\hline Diabetes mellitus & 6/77 (8) & $962 / 5417(18)$ & 0.02 \\
\hline Health care-associated & 1/77 (1) & 1349/5514 (24) & $<0.001$ \\
\hline Congenital heart disease & $11 / 66(17)$ & $533 / 4813(11)$ & 0.16 \\
\hline Native valve predisposition & 25/76 (33) & 1609/5403 (30) & 0.55 \\
\hline Mechanical aortic valve & 12/77 (16) & $504 / 5507$ (9) & 0.07 \\
\hline Bioprosthetic aortic valve & 6/77 (8) & 426/5507 (8) & 0.9 \\
\hline Mechanical mitral valve & 11/77 (14) & 404/5504 (7) & 0.03 \\
\hline Other & $5 / 77(7) \dagger$ & $604 / 5504(11)$ & 0.27 \\
\hline \multicolumn{4}{|l|}{ Diagnosis } \\
\hline Blood culture growth & $73 / 77(95)$ & $4586 / 5430(84)$ & 0.01 \\
\hline Other specimens culture positive & $29 / 76(38) \ddagger$ & $2787 / 5489(51)$ & 0.03 \\
\hline \multicolumn{4}{|l|}{ ECHO findings } \\
\hline Intracardiac vegetations & $53 / 75(71)$ & $4455 / 5383(83)$ & 0.01 \\
\hline Aortic Valve & 26/53 (49) & 1959/4455 (44) & 0.49 \\
\hline Mitral Valve & $25 / 53(47)$ & 2043/4455 (46) & 0.9 \\
\hline Tricuspid Valve & $1 / 52(2)$ & $578 / 4394(13)$ & 0.02 \\
\hline Other & $4 / 53(8) \S$ & $611 / 4455(14)$ & 0.23 \\
\hline New regurgitation & $46 / 75(61)$ & $3124 / 5368$ (58) & 0.62 \\
\hline Paravalvular complications & $15 / 75(20)$ & $1117 / 5354(21)$ & 0.85 \\
\hline \multicolumn{4}{|l|}{ Outcome } \\
\hline Stroke & 19/76 (25) & $898 / 5410(17)$ & 0.05 \\
\hline Embolic stroke & 10/18 (56) & 648/780 (83) & 0.008 \\
\hline Haemorrhagic stroke/intracranial haemorrhage & $8 / 18(44)$ & 132/780 (17) & 0.006 \\
\hline Congestive heart failure & $11 / 74(15)$ & 1646/5397 (30) & 0.004 \\
\hline Embolization, excluding central nervous system & 15/73 (21) & 1205/5399 (22) & 0.79 \\
\hline Intracardiac abscess & 14/75 (19) & $721 / 5402(13)$ & 0.17 \\
\hline Mycotic aneurysm & $3 / 74(4)$ & 104/5351 (19) & 0.15 \\
\hline Surgery & $31 / 77(40)$ & 2433/5482 (44) & 0.49 \\
\hline Median days in hospital (interquartile range) & $23(15-42)$ & $28(15-44)$ & 0.19 \\
\hline In-hospital death & 3/77 (4) & $998 / 5508(18)$ & 0.001 \\
\hline Death within 1 year of admission & $6 / 57(11)^{* *}$ & $1627 / 4208(39)^{* *}$ & 0.001 \\
\hline
\end{tabular}

*Values are reported as $n / n(\%)$, unless otherwise noted.

${ }^{\dagger}$ Aortic valve- homograft 1, unknown repair 1; mitral valve - repair with prosthesis 1, other 2 . TEE $=$ Transesophageal ECHO.

${ }^{\ddagger}$ Specimens that were culture-positive were heart valve (20), joint fluid (2), pacemaker wire (1), urine (1) and other (5) §Myocardial wall 2, chordae 1, intracardiac device 1.

**1 year mortality data was available on $57(74 \%)$ of HE and $4208(76 \%)$ of non-HE subjects.

doi:10.1371/journal.pone.0063181.t002

susceptibility testing. Cardiac surgery was performed on $31(40 \%)$ patients a median of four days (IQR 1-19) after admission. The aortic valve was replaced in 17 patients, mitral valve in 13 , tricuspid valve in one and an intracardiac device was removed in one patient.

\section{Outcomes}

The in-hospital mortality of $\mathrm{HE}$ was less than one quarter that of the non-HE $(3,4 \%$ vs $998,18 \% ; \mathrm{p}<0.001)$. Of the three HE deaths with one had been treated surgically. Heart failure was significantly less frequent in $\mathrm{HE}$ than non-HE $(15 \%$ vs. $30 \%$, 
$p=0.004)$. Stroke complicated a higher proportion of cases with HE than non-HE $(25 \%$ vs. $17 \%, p=0.05)$ and there was a relative excess of haemorrhagic stroke over embolic stroke in HE $(44 \%$ vs $17 \%, p=0.006)$. The presence of a stroke increased the length of stay by 20 days despite occurring in a significantly younger age group (Table 3). On multivariable regression analysis the independent factors associated with stroke were increasing age in 10 year intervals (OR 0.62; CI 0.49-0.90; p<0.01) and mitral valve vegetations (OR 3.60; CI 1.34-9.65; $\mathrm{p}<0.01$ ). Eleven of 25 $(44 \%)$ cases of $\mathrm{HE}$ with mitral valve vegetations suffered a stroke compared with $484 / 2009(24 \%)$ in non-HE $(p=0.03)$. The frequency of systemic embolization, excluding central nervous system, intracardiac abscess and mycotic aneurysm were not significantly different in HE than non-HE (Table 2).

At one year follow-up, three additional cases of HE had died (heart failure 1, unrelated causes 1, unknown 1); however the cumulative death rate was significantly lower than non-HE $(6,11 \%$ vs $1627,39 \%$; $<<0.001$ ) (Table 2). Four cases had undergone valvular surgery; three had been treated medically and one surgically.

There was one possible relapse 4 months after completing therapy with an unspecified HACEK organism. This organism was not available for further speciation. In addition one patient with $\mathrm{HE}$ had another episode of endocarditis with a methicillin susceptible S. aureus.

HACEK native and prosthetic valve endocarditis. Comparison of the clinical features of native valve and prosthetic valve $\mathrm{HE}$ demonstrated that native valve $\mathrm{HE}$ occurred at an older age (median 56.3 (range 41-67) vs median 43.8 (range $32-54$ ) years, $\mathrm{p}=0.003$ ), and that a higher proportion had Osler's nodes $(5,20 \%$ vs $0,0 \% ; \mathrm{p}=0.002)$ and systemic embolization $(10,37 \%$ vs $5,12 \% \mathrm{v} ; \mathrm{p}=0.01)$ than prosthetic valve HE (Table 4). There was no significant difference in the proportion with stroke $(7,26 \%$ vs $11,24 \% ; \mathrm{p}=0.85)$, or congestive heart failure $(5,19 \%$ vs $6,14 \% ; p=0.74)$ or surgical treatment $(8$,
$30 \%$ vs $22,45 \% ; \mathrm{p}=0.23)$ or length of median hospital stay between these groups.

Of those with PVE 8 (30\%) required surgical treatment and 19 $(70 \%)$ were treated with medical therapy alone. There were no inhospital deaths in either treatment group. Of the 24 PVE patients with 1 year follow-up data, there was one death (cause unknown) and three who required cardiac surgery in the medically treated group, but no deaths, relapses or further surgery requirement in the surgically treated group. By comparison, among those with native valve $\mathrm{HE}$, there were two in-hospital deaths and 1 death with-in the 1 year follow-up period.

\section{Discussion}

This report describes the findings of a large series of HE and non-HE cases of bacterial endocarditis reported in a standardised manner in which geographic distribution, frequency of clinical features, risk factors and outcomes have been compared. Both groups were subject to referral bias from transfers to the study centres $[19,20]$, but this is unlikely to confound these comparisons as the proportion transferred was very similar in the two groups, and the pattern of features of the transferees with HE was similar to that reported in the ICE cohort. However the frequency of some clinical features are influenced by transfers between hospitals, and the results need to be interpreted in the light of this limitation.

The marked geographic difference in the prevalence of HE (10fold) between the highest (New Zealand) and the lowest countries (United States of America) confirms the findings of an earlier, smaller sample of cases in the ICE cohort [11]. The range is similar to the range of $0.8-6.1 \%$ reported in recent single and multi-centre studies. [3-5]. The high prevalence of HE in New Zealand is unlikely to be due to referral patterns given the low proportion transferred from another facility. Other possible reasons for the variation include the prevalence of risk factors such as frequency of prosthetic devices [12], oral health [21],

Table 3. Univariate and multivariate analysis for the risk of stroke in HACEK endocarditis*.

\begin{tabular}{|c|c|c|c|c|}
\hline & \multirow{2}{*}{$\begin{array}{l}\text { No stroke } \\
n=57 \dagger\end{array}$} & \multirow{2}{*}{$\begin{array}{l}\text { Stroke } \\
n=19 \dagger\end{array}$} & \multirow{2}{*}{$\begin{array}{l}\begin{array}{l}\text { Univariate } \\
\text { analysis }\end{array} \\
P \text { value }\end{array}$} & \multirow{2}{*}{$\begin{array}{l}\text { Multivariate analysis } \\
\text { Odds Ratio ( } 95 \% \text { confidence } \\
\text { interval) }\end{array}$} \\
\hline & & & & \\
\hline Prosthetic valve endocarditis & 20/57 (35) & $7 / 19(37)$ & 0.9 & \\
\hline Median age (interquartile range), $y$ & $51(38-60)$ & $41(25-54)$ & 0.02 & $0.62 ;(\mathrm{Cl} 0.49-0.90) P<0.01$ \\
\hline$>1$ month from 1st manifestation & $13 / 57(23)$ & $5 / 19(26)$ & 0.8 & \\
\hline Conjunctival haemorrhages & $1 / 52(2)$ & $5 / 19(26)$ & 0.001 & \\
\hline Osler's nodes & $4 / 52(8)$ & $1 / 18(6)$ & 0.8 & \\
\hline Vascular/immunologic evidence of endocarditis & $13 / 57(23)$ & $11 / 19(58)$ & 0.004 & \\
\hline Aortic valve vegetation & $22 / 37(59)$ & $4 / 16(25)$ & 0.02 & \\
\hline Mitral valve vegetation & $14 / 37(38)$ & $11 / 16(69)$ & 0.04 & $3.60(\mathrm{Cl} 1.34-9.65) P<0.01$ \\
\hline Aortic valve surgery & $14 / 21(67)$ & $4 / 9(44)$ & 0.26 & \\
\hline Mitral valve surgery & $6 / 21(29)$ & $7 / 9(78)$ & 0.01 & \\
\hline Embolization & $10 / 56(18)$ & $5 / 17(29)$ & 0.3 & \\
\hline Mycotic Aneurysm & $0 / 57(0)$ & $3 / 19(16)$ & 0.003 & \\
\hline Median days in hospital (interquartile range) & $22(14-34)$ & $42(21-60)$ & 0.002 & \\
\hline In-hospital death & $2 / 57(4)$ & $1 / 19(5)$ & 0.7 & \\
\hline
\end{tabular}


Table 4. Comparison between the features of native valve HACEK endocarditis and prosthetic valve HACEK endocarditis*.

\begin{tabular}{|c|c|c|c|}
\hline & Native valve Endocarditis & $\begin{array}{l}\text { Prosthetic valve } \\
\text { endocarditis }\end{array}$ & $P$ value \\
\hline & $n=47$ & $\mathbf{n}=\mathbf{2 7}$ & \\
\hline Duke diagnosis definite & $43 / 47(92)$ & $21 / 27(78)$ & 0.01 \\
\hline Median age (interquartile range), $y$ & $43.8(32-54)$ & $56.3(41-67)$ & 0.003 \\
\hline Osler's nodes & $0 / 43(0)$ & $5 / 25(20)$ & 0.002 \\
\hline Worsening of old murmur or presence of new murmur & $30 / 47(64)$ & $8 / 27(30)$ & 0.005 \\
\hline $\mathrm{ECHO}$ evidence of new regurgitation & $36 / 47(77)$ & $10 / 27(37)$ & $<0.001$ \\
\hline Intracardiac vegetations & $36 / 46(78)$ & $15 / 27(56)$ & 0.02 \\
\hline Aortic valve & $17 / 36(47)$ & $9 / 15(60)$ & 0.4 \\
\hline Mitral valve & $18 / 36(50)$ & $7 / 15(47)$ & 0.8 \\
\hline Aortic valve surgery & $11 / 22(50)$ & $7 / 8(88)$ & 0.06 \\
\hline Stroke & $11 / 46(24)$ & $7 / 27(26)$ & 0.85 \\
\hline Embolic & $6 / 11(55)$ & $4 / 6(67)$ & 1.0 \\
\hline Intracerebral haemorrhage & $5 / 11(45)$ & $2 / 6(33)$ & 1.0 \\
\hline Other systemic Embolization & $5 / 43(12)$ & 10/27 (37) & 0.01 \\
\hline Congestive heart failure & $6 / 44(14)$ & $5 / 27(19)$ & 0.13 \\
\hline Surgery & $21 / 47(45)$ & $8 / 27(30)$ & 0.23 \\
\hline In-hospital death & 2/47 (4) & $0 / 27(0)$ & 0.28 \\
\hline Median days in hospital (interquartile range) & $21(12-37)$ & $24(17-43)$ & 0.2 \\
\hline Death within 1 year of admission & $3 / 33(9) \dagger$ & $1 / 22(5) \dagger$ & 0.8 \\
\hline
\end{tabular}

transmission pathways of HACEK organisms within populations [22], regional health care access, and diagnostic bias.

Some clinical features varied with the causative species. $H$. parainfluenzae was the commonest cause of $\mathrm{HE}$, as has been reported in population based studies [23]. H. parainfluenzae endocarditis was less likely to have an insidious onset than both A. actinomycetemcomitans and C. hominis confirming previous reports [7]. C. hominis was strongly associated with aortic valve infection and $A$. actinomycetemcomitans endocarditis was a frequent cause of PVE, and vascular immunological manifestations $[6,7,9,10]$. Despite this, we found that HE has sufficient important clinical features in common that distinguish it from non-HE to retain clinical usefulness. These features include younger age of presentation, community acquisition, a higher proportion with vascular/immunological manifestations, a lower proportion with co-morbidities and an excellent outcome.

Prosthetic valve endocarditis was common (35\%), although the prevalence of HACEK PVE was not significantly higher than nonHE PVE in this study $(p=0.07)$. However, the comparator includes a heterogeneous group of organisms with variable propensity to cause PVE. For example, previous studies of the ICE cohort have found the proportion of PVE in Staphylococcus aureus IE to be $16 \%$, viridans streptococcal IE to be $15 \%$, and coagulase-negative staphylococcal IE to be $32 \%$ [11]. Thus it appears that HACEK organisms have a predilection for prosthetic valves. This finding is more marked in late PVE $(>1$ year after surgery) as HE causes late PVE in a large majority of cases [12], but only about half of cases of $S$. aureus and coagulase-negative staphylococci PVE, suggesting mechanical valves are a particular risk for $\mathrm{HE}$ [17]. In addition this study may underestimate the true proportion with PVE because of the high number of native valve
HE cases transferred from other centres. Pre-existing native valve and congenital cardiac abnormalities were common in $\mathrm{HE}$ but there was no significant increase in these conditions compared with non-HE. Previous studies have suggested these risk factors may occur more frequently in $\mathrm{HE}$, but this will be subject to changes in the epidemiology of native valve lesions such as rheumatic fever and the widespread availability of cardiac surgery [22].

Most cases of HE were treated with a third generation cephalosporin and a minority with ampicillin with or without an aminoglycoside; however there were insufficient cases to correlate outcomes with these recommended regimens [24,25]. The incidence of penicillin resistant strains was limited to an isolate of $A$. aphrophilus species. $\beta$-lactamase producing strains of $C$. hominis have been reported but not in $A$. actinomycetemcomitans to our knowledge [26]. The proportion of all $\mathrm{HE}$ cases requiring cardiac surgery $(40 \%)$ was similar to non-HE and to that reported in the literature [12,27]. However in PVE the requirement for surgery was lower $(30 \%)$ which compares favourably with published rates for PVE overall $(49 \%)$ [12,27]. The favourable outcome of both medically and surgically treated HACEK PVE demonstrates that $\mathrm{HE}$ is readily controlled and treated with antimicrobial agents despite the presence of a prosthetic valve.

The outcome of HE was excellent overall with an in-hospital mortality of $3 \%$ which is less than one quarter of the mortality for non-HE and one sixth that of $S$. aureus endocarditis [28]. Heart failure was diagnosed in $15 \%$ of cases compared with $30 \%$ in non$\mathrm{HE}$, and $37 \%$ reported for $S$. aureus endocarditis [27,28]. The younger age group and lack of co-morbidities, in addition to pathogen-specific characteristics may favour a good in-hospital and 1 year outcomes. These results would not be affected by 
survivor bias given the very high survival rate of $\mathrm{HE}$. With respect to PVE, the numbers were too small to make meaningful comparison for other major complications including stroke, congestive heart failure and abscess formation.

The major complication of HE was stroke (25\%), and this complication almost doubled the length of hospitalisation. This figure over-represents the true incidence of stroke in HE as there was an increased frequency of stroke in those transferred from other facilities. Nevertheless stroke is conspicuously common in HE compared with non-HE, and the reported frequency in $S$. aureus endocarditis (20\%) and viridans streptococcal IE $(8 \%)$ in the ICE cohort [29]. Mitral valve IE was an important risk factor for stroke as reported previously, but organism specific effects on the nature of the vegetations in HE may also make a significant contribution to the prevalence of stroke, as $44 \%$ of patients with mitral valve $\mathrm{HE}$ suffering a stroke compared with $24 \%$ of non-HE. This may be related to the long antecedent history with organisms such as A. actinomycetemcomitans [7].

While embolism was the predominant cause of stroke in $\mathrm{HE}$ there was relative excess of haemorrhagic stroke. The reasons for this are not clear but it is possible micro-vascular/immunological manifestations of IE which were significantly more frequent in $\mathrm{HE}$ than non-HE and might contribute to the development of cerebral microbleeds which are a strong predictor of subsequent intracranial haemorrhage [30]. Anticoagulant therapy is unlikely to contribute to the occurrence of stroke but may increase the conversion of embolic to haemorrhagic events. [31].

There are several additional limitations of this study. Because of small numbers both possible and definite cases were included to increase statistical power. Despite this there were a limited number of cases of HACEK endocarditis and the observational design and long-term follow-up limited to one year limits our ability to draw any firm conclusions regarding optimal antimicrobial therapy or surgical treatment strategies. Furthermore the self selection of centres to participate in the ICE study, and the heavy weighting toward Europe, North America and Australasia with few sites in Asia, and Africa has meant that the population sample may not be representative of any specific region. Thus important geographical differences may have been missed and any epidemiological inferences from this study are limited.

Our findings suggest that there is sufficient similarity in presentation and outcome to justify considering the HACEK organisms as a group at present. Despite the high prevalence of stroke, HE has a remarkably low mortality rate, suggesting that current antibiotic therapy with surgery when needed, is very effective. The reasons why HE shows apparent disparities in geographical distribution, occurs in a younger age group, has a propensity to infect prosthetic valves, and is associated with a high incidence of stroke are worthy of further investigation.

\section{Acknowledgments}

In addition to all of the named ICE investigators at each site, we would like to acknowledge the support given to this project from all of the personnel at each site and at the coordinating center that have allowed this project to move forward.

\section{Study Investigators}

Argentina: Liliana Clara, MD, Marisa Sanchez, MD (Hospital Italiano). Francisco Nacinovich, MD, Pablo Fernandez Oses, MD, Ricardo Ronderos, MD, Adriana Sucari,MD, Jorge Thierer, MD (Instituto Cardiovascular). José Casabé, MD, PhD,Claudia Cortes, MD,(Hospital Universitario de la Fundaciòn Favaloro)

Javier Altclas, MD,Sanatorio, Silvia Kogan, MD (Sanatorio de la Trinidad Mitre). Australia: Denis Spelman, MD (Alfred Hospital). Eugene Athan,MD, Owen Harris, MBBS,(Barwon Health). Karina Kennedy, MBBS,Ren Tan, MBBS (Canberra Hospital). David Gordon, MBBS, PhD,
Lito Papanicolas, MBBS (Flinders Medical Centre). Damon Eisen, MBBS, MD, Leeanne Grigg, MBBS, Alan Street, MBBS (Royal Melbourne Hospital). Tony Korman, MD, Despina Kotsanas,BSc (Hons) (Southern Health). Robyn Dever, MD, Phillip Jones, MD, Pam Konecny, MD, Richard Lawrence, MD, David Rees, MD, Suzanne Ryan,MHSc (St. George Hospital). Michael P. Feneley,MD, John Harkness, MD, Phillip Jones, MD, Suzanne Ryan, MHSc (St. Vincent's). Austria:Phillip Jones, MD, Suzanne Ryan, MHSc (Sutherland). Phillip Jones, MD, Jeffrey Post, MD, Porl Reinbott, Suzanne Ryan, MHSc (The University of New South Wales). Rainer Gattringer, MD, Franz Wiesbauer, MD (Vienna General Hospital). Brazil: Adriana Ribas Andrade, Ana Cláudia Passos de Brito, Armenio Costa Guimarães,MD (Ana Neri Hospital). Max Grinberg, MD, PhD, Alfredo José Mansur MD, $\mathrm{PhD}$, Rinaldo Focaccia Siciliano, MD, Tania Mara Varejao Strabelli, MD, Marcelo Luiz Campos Vieira, MD (Heart Institute (Incor), University of Sao Paulo Medical School).Regina Aparecida de Medeiros Tranchesi, MD, Marcelo Goulart Paiva, MD (Hospital 9 de Fulho). Claudio Querido Fortes, MD (Hospital Universitario Clementino Fraga Filho/UFRf). Auristela de Oliveira Ramos,MD (Instituto Dante Pazzanese de Cardiologia). Giovanna Ferraiuoli, MD, Wilma Golebiovski,MD, Cristiane Lamas,MD, PhD, Marisa Santos, MD,PhD, Clara Weksler, MD (Instituto Nacional de Cardiologi). Canada: James A. Karlowsky, MD, Yoav Keynan, MD, Andrew M. Morris, MD, Ethan Rubinstein, MD, LL.B (University of Manitoba). Ghile: Sandra Braun Jones, MD, Patricia Garcia, MD (Hospital Clínico Pont. Universidad Católica de Chile). M Cereceda,MD, Alberto Fica, Rodrigo Montagna Mella,Md (Hospital Clinico Universidad de Chile). Groatia: Bruno Barsic, MD, PhD, Suzana Bukovski, MD,PhD Vladimir Krajinovic,MD, Ana Pangercic,MD, Igor Rudez,MD, Josip Vincelj,MD, PhD (University Hospital for Infectious Diseases). Czech Republic: Tomas Freiberger, MD, PhD, Jiri Pol,MD, Barbora Zaloudikova,MSc (Centre for Cardiovascular Surgery and Transplantation). Egypt: Zainab Ashour,MD, Amani El Kholy,MD, Marwa Mishaal, MD, Hussien Rizk,MD (Cairo University Medical School). France: Neijla Aissa,MD, Corentine Alauzet,MD, Francois Alla, MD, PhD,CHU Catherine Campagnac,RN, Thanh Doco-Lecompte,MD, Christine Selton-Suty, MD (CHU Nancy-Brabois). Jean-Paul Casalta, MD, PierreEdouard Fournier, MD, Gilbert Habib, MD, Didier Raoult,MD,PhD, Franck Thuny,MD (Faculté de Médecine de Marseille). Francois Delahaye,MD, $\mathrm{PhD}$, Armelle Delahaye, Francois Vandenesch,MD (Hospital Louis Pradel). Erwan Donal,MD, Pierre Yves Donnio,PhD, Christian Michelet,MD, $\mathrm{PhD}$, Matthieu Revest,MD, Pierre Tattevin,MD,PhD, Jérémie Violette,MD (Pontchaillou University). Florent Chevalier,MD, Antoine Jeu,MD, Dan MD Rusinaru,MD, Claire Sorel,MD, Christophe Tribouilloy,MD,PhD (South Hospital Amiens). Yvette Bernard,MD, Catherine Chirouze,MD, Bruno Hoen,MD,PhD, Joel Leroy,MD, Patrick Plesiat,MD (University Medical Center of Besançon). Germany: Christoph Naber, MD, PhD, Carl Neuerburg (Universitaetskliniken Bergmannsheil Bochum). Bahram Mazaheri,PhD, Christoph Naber,MD, PhD, Carl Neuerburg (University Essen). Greece: Sofia Athanasia, MD, Efthymia Giannitsioti,MD (Attikon University General Hospital). Elena Mylona MD, Olga Paniara MD, PhD, Konstantinos Papanicolaou,MD, John Pyros MD, Athanasios Skoutelis $\mathrm{MD}, \mathrm{PhD}$ (Evangelismos General Hospital of Athens) India: Gautam Sharma,MD (All India Institute of Medical Sciences). Johnson Francis, MD,DM, Lathi Nair,MD,DM Vinod Thomas, MD,DM, Krishnan Venugopal,MD,DM (Medical College Calicut). Ireland: Margaret Hannan, MB, BCh BAO, MSc, John Hurley,MB, BCh (Mater Hospitals). Israel: Dan Gilon, MD, Sarah Israel,MD, Maya Korem, MD, Jacob Strahilevitz,MD (Hadassah-Hebrew University).Ethan Rubinstein, MD, LL.B , Jacob Strahilevitz,MD (Tel Aviv University School of Medicine). Italy: Marie Françoise Tripodi, MD (Università degli Studi di Salerno); Roberta Casillo, MD, PhD, Susanna Cuccurullo, MSc, Giovanni Dialetto, MD, Emanuele DuranteMangoni, MD, PhD, Mattucci Irene, MD, Enrico Ragone, MD, PhD, Riccardo Utili, MD, PhD (II Università di Napoli). Enrico Cecchi,MD, Francesco De Rosa, MD, Davide Forno,MD, Massimo Imazio, MD, Rita Trinchero, MD (Maria Vittoria Hospital). Alessandro Tebini, MD, Paolo Grossi, MD, PhD, Mariangela Lattanzio, MD, Antonio Toniolo, MD (Ospedale di Circolo Varese). Antonio Goglio, MD, Annibale Raglio, MD, DTM\&H, Veronica Ravasio, MD, Marco Rizzi, MD, Fredy Suter, MD (Ospedali Riuniti di Bergamo). Giampiero Carosi, MD, Silvia Magri, MD, Liana Signorini, MD (Spedali Civili - Università di Brescia). Lebanon: Tania Baban,MD, Zeina Kanafani, MD, MS, Souha S.Kanj, MD, Jad Sfeir, MD , Mohamad Yasmine, MD (American University of Beirut Medical Center). Malaysia: Imran Abidin,MD (University of Malaya Medical Center). Syahidah Syed Tamin, MD (National Heart Institute) Mexico: Eduardo Rivera Martínez,MD, Gabriel Israel Soto Nieto,MD (Instituto Nacional de 
Cardiología Ignacio Chávez). Netherlands: Jan T.M. van der Meer, $\mathrm{MD}, \mathrm{PhD}$ (University of Amsterdam). New Zealand: Stephen Chambers, MD, MSc (University of Otago), David Holland, MB, ChB, PhD (Middlemore Hospital), Arthur Morris,MD (Diagnostic Medlab), Nigel Raymond, MB, ChB (Wellington Hospital), Kerry Read, MB, ChB (North Shore Hospital). David R. Murdoch, MD, MSc, DTM\&H (University of Otago). Romania: Stefan Dragulescu, MD,PhD, Adina Ionac, MD, $\mathrm{PhD}$, Cristian Mornos,MD (Victor Babes University of Medicine and Pharmacy). Russia: O.M. Butkevich,PhD (Learning-Scientific Centre of Medical Centre of Russian Presidential Affairs Government Medical Centre of Russian). Natalia Chipigina, PhD, Ozerecky Kirill, MD, Kulichenko Vadim, Tatiana Vinogradova,MD, PhD (Russian Medical State University) Saudi Arabia: Jameela Edathodu, MBBS, Magid Halim,MBBS (King Faisal Specialist Hospital \& Research Center). Singapore: Luh-Nah Lum,BSN, Ru-San Tan,MBBS (National Heart Centre). Slovenia: Tatjana Lejko-Zupanc, MD, $\mathrm{PhD}$, Mateja Logar, MD, PhD, Manica Mueller-Premru, MD, PhD (Medical Center Ljublijana). South Africa: Patrick Commerford, MD, Anita Commerford, MD, Eduan Deetlefs, MD, Cass Hansa, MD, Mpiko Ntsekhe, MD (University of Cape Town and Groote Schuur Hospital). Spain: Manuel Almela, MD, Yolanda Armero, MD, Manuel Azqueta, MD, Ximena Castañeda, MD, Carlos Cervera, MD, Ana del Rio,MD,PhD, Carlos Falces, MD, Cristina Garcia-de-la-Maria, PhD, Guillermina Fita, MD, Jose M. Gatell, MD, PhD, Francesc Marco,MD, $\mathrm{PhD}$, Carlos A. Mestres, MD, PhD, José M. Miró, MD, PhD, Asuncion Moreno, MD, PhD, Salvador Ninot, MD, Carlos Paré, MD, PhD, Joan Pericas, MD, Jose Ramirez, MD, PhD, Irene Rovira, MD, Marta Sitges, MD (Hospital Clinic - IDIBAPS. University of Barcelona, Barcelona, Spain). Ignasi Anguera, MD, PhD, Bernat Font,MD, Joan Raimon Guma, MD (Hospitál de Sabadell). Javier Bermejo, Emilio Bouza, MD,PhD, Miguel Angel Garcia Fernández, MD, Victor Gonzalez-Ramallo, MD, Mercedes Marín, MD, Patricia Muñoz, MD,PhD, Miguel Pedromingo, MD, Jorge Roda, Marta Rodríguez-Créixems,MD,PhD, Jorge Solis, MD (Hospital General Universitario Gregorio Marañón). Benito Almirante,MD, Nuria Fernandez-Hidalgo,MD, Pilar Tornos,MD (Hospital Universitari Vall d'Hebron). Arístides de Alarcón, Ricardo Parra (Hospital Universitario Virgen del Rocío). Sweden: Eric Alestig,MD, Magnus Johansson,MD,PhD, Lars Olaison,MD, PhD, Ulrika Snygg-Martin,MD (Sahlgrenska Universitetssjukhuset/Östra). Thailand: Orathai Pachirat,MD, Pimchitra Pachirat,MD, Burabha Pussadhamma,MD, Vichai Senthong,MD (Khon Kaen University). United Kingdom: Anna Casey,MBBS, Tom Elliott, PhD,DSc, Peter Lambert, BSc,PhD,DSc, Richard Watkin,MBBS (Queen Elizabeth Hospital). Christina Eyton, John L. Klein,MD (St. Thomas' Hospital). United States of America: Suzanne

\section{References}

1. Lerner PI, Weinstein L (1966) Infective endocarditis in the antibiotic era. N EnglJ Med274:199-206.

2. Pelletier LL, Petersdorf RG (1977) Infective endocarditis: a review of 125 cases from the University of Washington Hospitals, 1963-72. Medicine 56:287-313.

3. Selton-Suty C, Célard M, Le Moing V, Doco-Lecompte T, Chirouze C, et al.; on behalf of the AEPEI Study Group ( 2012) Preeminence of Staphylococcus aureus in Infective Endocarditis: A 1-Year Population-Based Survey. Clin Infect Dis 54:1230-1239.

4. Ferreiros E, Nacinovich F, Casabé JH, Modenesi JC, Swieszkowski S, et al. (2006) EIRA-2 Investigators. Epidemiologic, clinical, and microbiologic profile of infective endocarditis in Argentina: a national survey. The Endocarditis Infecciosa en la RepúblicamArgentina-2 (EIRA-2) Study. Am Heart J 151:54552.

5. Tleyjeh IM, Steckelberg JM, Murad HS, Anavekar NS, Ghomrawi HM, et al. (2005) Temporal trends in infective endocarditis: a population-based study in Olmsted County, Minnesota. JAMA 293:3022-8

6. Brouqui P, Raoult D (2001) Endocarditis due to rare and fastidious bacteria. Clin Microbiol Rev 14:177-207.

7. Das M, Badley AD, Cockerill FR, Steckelberg JM, Wilson WR (1997) Infective endocarditis caused by HACEK microorganisms. Ann Rev Med 48:25-33

8. Darras-Joly C, Lortholary O, Mainardi JL, Etienne J, Guillevin L, et al. (1997) Haemophilus endocarditis: report of 42 cases in adults and review. Haemophilus Endocarditis Study Group. Clin Infect Dis24:1087-94.

9. Malani AN, Aronoff DM, Bradley SF, Kauffman CA (2006) Cardiobacterium hominis endocarditis: Two cases and a review of the literature. Eur J Clin Microbiol Infect Dis25:587-95.

10. Paturel L, Casalta JP, Habib G, Nezri GM, Raoult D (2004) Actinobacillus actinomycetemcomitans endocarditis. Clinical Microbiol Infect 10:98-118.

11. Murdoch DR, Corey GR, Hoen B, Miró JM, Fowler VG Jr, et al. (2009) Clinical presentation, etiology, and outcome of infective endocarditis in the 21 st century: the International Collaboration on Endocarditis-Prospective Cohort Study. Arch Intern Med 169:463-73.
Bradley,MD, Carol Kauffman,MD (Ann Arbor VA Medical Center). Roger Bedimo,MD, MS (Dallas VA Medical Center). Vivian H. Chu,MD, MHS, G. Ralph Corey, MD, Anna Lisa Crowley, MD, MHS, Pamela Douglas, MD, Laura Drew, RN, BSN, Vance G. Fowler, MD, MHS, Thomas Holland,MD, Tahaniyat Lalani, MBBS, MHS, Daniel Mudrick, MD, Zaniab Samad, MD, MHS, Daniel Sexton, MD, Martin Stryjewski, MD,MHS, Andrew Wang,MD, Christopher W. Woods, MD,MPH (Duke University Medical Center). Stamatios Lerakis,MD (Emory University). Robert Cantey, MD, Lisa Steed,PhD, Dannah Wray, MD,MHS (Medical University of South Carolina). Stuart A. Dickerman, MD (New York University Medical Center). Hector Bonilla, MD, Joseph DiPersio, MD, PhD, Sara-Jane Salstrom, RN (Summa Health System). John Baddley, MD, Mukesh Patel, MD (University of Alabama at Birmingham). Gail Peterson, MD, Amy Stancoven, MD (UT-Southwestern Medical Center). Luis Afonso,MD, Theresa Kulman, RN, Donald Levine, MD, Michael Rybak, PharmD, MPH (Wayne State University). Christopher H. Cabell, MD, MHS (Quintiles)

ICE Coordinating Genter: Khaula Baloch, MPH, Vivian H. Chu, MD, MHS , G. Ralph Corey, MD, Christy C. Dixon, Vance G. Fowler, Jr, MD, MHS, Tina Harding, RN, BSN, Marian Jones-Richmond, Paul Pappas, MS, Lawrence P. Park, PhD, Thomas Redick, MPH, Judy Stafford, MS

ICE Publications Committee: Kevin Anstrom, $\mathrm{PhD}$, Eugene Athan, MD, Arnold S. Bayer, MD, Christopher H. Cabell, MD, MHS, Vivian H. Chu, MD, MHS, G. Ralph Corey, MD, Vance G. Fowler, Jr, MD, MHS, Bruno Hoen, MD,PhD, A W Karchmer MD, José M. Miró, MD, PhD, David R. Murdoch, MD,MSc, DTM\&H, Daniel J. Sexton MD, Andrew Wang MD

ICE Steering Committee: Arnold S. Bayer, MD, Christopher H Cabell, MD, MHS, Vivian Chu MD, MHS. G. Ralph Corey MD, David T. Durack, MD, D Phil, Susannah Eykyn MD, Vance G. Fowler, Jr, MD, MHS, Bruno Hoen MD,PhD, José M. Miró, MD, PhD, Phillipe Moreillon, MD PhD, Lars Olaison, MD, PhD, Didier Raoult, MD, $\mathrm{PhD}$,Ethan Rubinstein MD,LLB, Daniel J, Sexton, MD

\section{Author Contributions}

Conceived and designed the experiments: DM PP GRG VC. Performed the experiments: SC DM AM DH PP MA NF-H BA EB DF AdR MH JH ZK TL SL NR KR TV GW DW GRC VG. Analyzed the data: SG DM PP VC. Wrote the paper: SC DM AM DH PP MA NF-H BA EB DF AdR MH JH ZK TL SL NR KR TV CW DW GRC VG.

12. Wang A, Athan E, Pappas PA, Fowler VG Jr, Olaison L, et al. (2007) Contemporary clinical profile and outcome of prosthetic valve endocarditis. JAMA 297:1354-61.

13. Li JS, Sexton DJ, Mick N, Nettles R, Fowler VG Jr, et al. (2000) Proposed modifications to the Duke criteria for the diagnosis of infective endocarditis. Clin Infect Dis 30:633-8.

14. Friedman ND, Kaye KS, Stout JE, McGarry SA, Trivette SL, et al. (2002) Healthcare associated blood stream infections in adults. Ann Intern Med 137:791-797.

15. Benito N, Miró JM, de Lazzari E, Cabell CH, del Río A, et al. (2009) ICE-PCS (International Collaboration on Endocarditis-Prospective Cohort Study) Investigators. Health care-associated native valve endocarditis: importance of nonnosocomial acquisition. Ann Intern Med 150(9):586-594.

16. Hunt SA, Abraham WT, Chin MH, Feldman AM, Francis GS, et al. (2005) ACC/AHA 2005 Guideline Update for the Diagnosis and Management of Chronic Heart Failure in the Adult: a report of the American College of Cardiology/American Heart Association Task Force on Practice. Circulation 112:e154-235.

17. Adams HP Jr, Brott TG, Crowell RM, Furlan AJ, Gomez CR, et al. (1994) Guidelines for the management of patients with acute ischemic stroke. A statement for healthcare professionals from a special writing group of the Stroke Council, American Heart Association. Circulation 90:1588-601.

18. Chu VH, Sexton DJ, Cabell CH, Reller LB, Pappas PA, et al. (2005) Repeat infective endocarditis: differentiating relapse from reinfection. Clin Infect Dis 41:406-9.

19. Kanafani ZA, Kanj SS, Cabell CH, Cecchi E, de Oliveira Ramos A, et al. (2010) Revisiting the effect of referral bias on the clinical spectrum of infective endocarditis in adults. Eur J Clin Microbiol Infect Dis 29:1203-10.

20. Fernández-Hidalgo N, Almirante $\mathrm{B}$, Tornos $\mathrm{P}$, González-Alujas MT, Planes AM, et al. (2011) Prognosis of left-sided infective endocarditis in patients transferred to a tertiary-care hospital. Prospective analysis of referral bias and 
influence of inadequate antimicrobial treatment. Clin Microbiol Infect 17:769775 .

21. Lawrence HP, Thomson WM, Broadbent JM, Poulton R (2008) Oral healthrelated quality of life in a birth cohort of 32-year olds. Community Dent Oral Epidemiol 36:305-16.

22. Hoen B, Alla F, Selton-Suty C, Béguinot I, Bouvet A, et al. (2002) Association pour l'Etude et la Prévention de l'Endocardite Infectieuse (AEPEI) Study Group. Changing profile of infective endocarditis: results of a 1-year survey in France. JAMA 288:75-81.

23. Tleyjeh IM, Abdel-Latif A, Rahbi H, Scott GG, Bailey KR, et al. (2007) A systematic review of population based studies of infective endocarditis. Chest 132:1025-1035.

24. Baddour LM, Wilson WR, Bayer AS, Fowler VG Jr, Bolger AF, et al. (2005) Infective endocarditis: diagnosis, antimicrobial therapy, and management of complications: a statement for healthcare professionals from the Committee on Rheumatic Fever, Endocarditis, and Kawasaki Disease, Council on Cardiovascular Disease in the Young, and the Councils on Clinical Cardiology, Stroke, and Cardiovascular Surgery and Anesthesia, American Heart Associationexecutive summary: endorsed by the Infectious Diseases Society of America. Circulation 111:e394-434.

25. Horstkotte D, Follath F, Gutschik E, Lengyel M, Oto A, et al. (2004) Guidelines on prevention, diagnosis and treatment of infective endocarditis executive summary; the task force on infective endocarditis of the European society of cardiology. Eur Heart J 25:267-276.

26. Lu PL, Hsueh PR, Hung CC, Teng LJ, Jang TN, et al. (2000) Infective endocarditis complicated with progressive heart failure due to beta-lactamaseproducing Cardiobacterium hominis. J Clin Microbiol 38:2015-7.

27. Chu VH, Miro JM, Hoen B, Cabell CH, Pappas PA, et al. (2009) International Collaboration on Endocarditis-Prospective Cohort Study Group. Coagulasenegative staphylococcal prosthetic valve endocarditis-a contemporary update based on the International Collaboration on Endocarditis: prospective cohort study. Heart 95:570-6.

28. Fowler VG Jr, Miro JM, Hoen B, Cabell CH, Abrutyn E, et al. (2005) Staphylococcus aureus endocarditis: a consequence of medical progress. JAMA 293:3012-21.

29. Dickerman SA, Abrutyn E, Barsic B, Bouza E, Cecchi E, et al. (2007) The relationship between the initiation of antimicrobial therapy and the incidence of stroke in infective endocarditis: An analysis from the ICE Prospective Cohort Study (ICE-PCS). Am Heart J 154:1086-94.

30. Okazaki S, Sakaguchi M, Hyun B, Nagano K, Tagaya M, et al. (2011) Cerebral microbleeds predict impending intracranial hemorrhage in infective endocarditis. Cerebrovasc Dis 32:483-8.

31. Paschalis C, Pugsley W, John R, Harrison MJ (1990) Rate of cerebral embolic events in relation to antibiotic and anticoagulant therapy in patients with bacterial endocarditis. Eur Neurol 30:87-9. 